\title{
Deskripsi Penggunaan Multimedia Interaktif pada Pembelajaran Matematika Bangun Ruang Sisi Lengkung Tabung
}

\section{Arianto A. Diu1 ${ }^{*}$, Abdul Djabar Mohidin², Nursiya Bito ${ }^{3}$, Sumarno Ismail $^{4}$, Resmawan ${ }^{5}$}

1,2,3,4,5 Jurusan Matematika, Fakultas MIPA, Universitas Negeri Gorontalo, Jl. Prof. Dr. Ing. B. J. Habibie, Tilongkabila, Kabupaten Bone Bolango, Gorontalo 96119, Indonesia

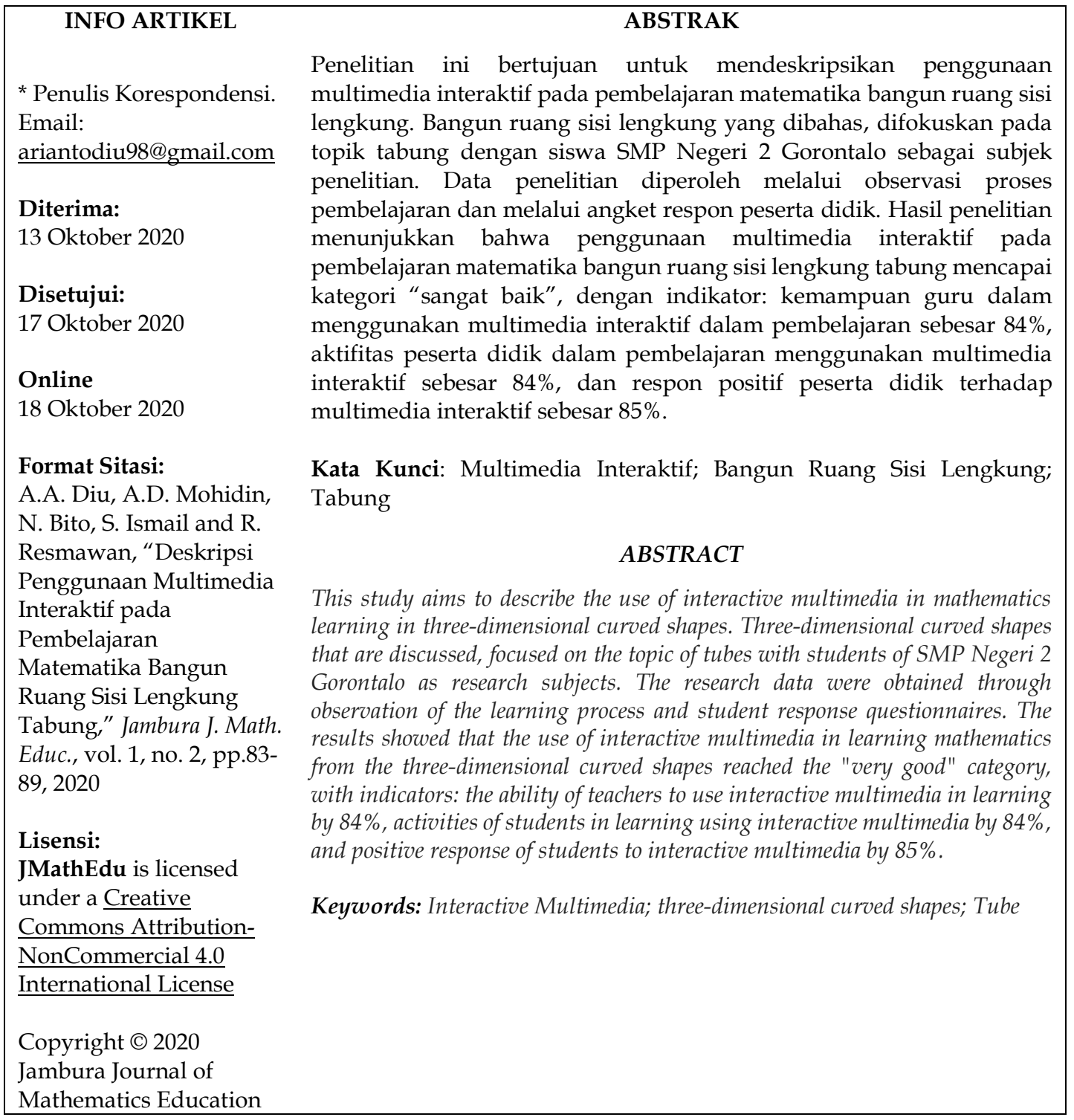


A.A. Diu, dkk | Deskripsi Penggunaan Multimedia Interaktif pada Pembelajaran Matematika ...

\section{Pendahuluan}

Perkembangan teknologi informasi yang semakin pesat sangat berpengaruh terhadap dunia pendidikan. Penggunaan teknologi informasi dalam dunia pendidikan mempunyai pengaruh positif karena memudahkan dalam memperoleh informasi. Salah satu pemanfaatan teknologi informasi dalam pendidikan dapat berupa multimedia yang melibatkan internet, komputer, televisi, media sosial, dan sejenisnya. Multimedia merupakan penggabungan dua kata "multi" dan "media". Multi berarti "banyak" sedangkan media berarti perantara atau bentuk jamaknya berarti medium [1]. Jadi secara istilah multimedia adalah kombinasi banyak atau beberapa media seperti teks, gambar, audio, video yang digunakan untuk menyampaikan pesan atau informasi. Dengan bantuan multimedia kita dapat menyajikan fenomena dan proses yang berbeda dengan jelas, mensimulasikan konten kompleks dan menyajikan berbagai tingkatan abstraksi [2]. Untuk itu, sangat penting menggunakan multimedia dalam bidang pendidikan terutama disekolah kerena berdampak positif terhadap pembelajaran baik itu bagi guru maupun peserta didik.

Penggunaan multimedia pada proses pembelajaran dapat membantu guru dalam menyampaikan materi yang diajarkan dan membuat variasi dalam mengajar agar tercipta suasana pembelajaran yang menyenangkan serta waktu yang digunakan lebih efisien. Multimedia juga dapat membantu peserta didik dalam memahami materi dan merangsang rasa ingin tahu mereka untuk belajar. Diharapkan kepada guru agar mampu menentukan pilihannya sesuai dengan kebutuhan pada saat melakukan kegiatan belajar mengajar. Hal ini dimaksudkan agar jangan sampai penggunaan multimedia menjadi penghalang proses belajar mengajar yang dilakukan guru dalam kelas. Harapan yang besar tentu saja agar multimedia menjadi alat bantu yang dapat mempercepat/mempermudah pencapaian tujuan pengajaran. Untuk itu guru harus memilih multimedia yang menarik perhatian dan mudah dipahami oleh peserta didik agar memperoleh proses pembelajaran yang efektif.

Multimedia interaktif menuntut adanya interaksi langsung dengan sumber informasi sehingga dapat meningkatkan rasa keingintahuan, minat, dan motivasi belajar bagi siswa yang memiliki kreatifitas tinggi [3]. Multimedia interaktif memiliki manfaat dalam pembelejaran baik bagi guru maupun peserta didik [4]. Menggunakan multimedia dalam pembelajaran dapat membantu guru dalam menyampaikan materi pelajaran sehingga memudahkan guru untuk menjelaskan serta meningkatkan kreativitas guru dalam mendesain tampilan multimedia agar peserta didik tertarik. Dengan demikian, penerapan multimedia interaktif dalam pembelajaran di sekolah dianggap sebagai salah satu solusi untuk menciptakan pembelajaran yang menarik dan inovatif [5].

Penggunaan multimedia sejauh ini telah banyak digunakan dalam proses pembelajaran, seperti penggunaan multimedia pada pembelajaran segiempat yang berjalan efektif [6][7][8]. Demikian halnya dengan penggunaan multimedia interaktif juga telah banyak digunakan dalam pembelajaran, seperti yang terdapat pada [9][10][11]. Sejalan dengan itu, juga telah ditunjukkan bahwa efektivitas penggunaan media pembelajaran elektronik interaktif ini lebih baik dari pada pembelajaran konvensional yang umumnya digunakan [12]. Banyaknya penelitian terkait multimedia interaktif dalam pembelajaran menunjukkan bahwa multimedia interaktif dapat menjadi solusi yang baik bagi pembelajaran di era kemajuan teknologi. Namun sepanjang yang kami ketahui, bahwa beberapa penelitian yang telah disebutkan sebelumnya belum ada yang mengaitkan 
A.A. Diu, dkk | Deskripsi Penggunaan Multimedia Interaktif pada Pembelajaran Matematika ...

antara multimedia interaktif dengan topik geometri khususnya pada bangun ruang sisi lengkung tabung.

Oleh karena itu, dalam makalah ini dideskripsikan tentang bagaimana penggunaan multimedia interaktif pada pembelajaran matematika bangun ruang sisi lengkung, tepatnya pada topik tabung.

\section{Metode}

Metode penelitian yang digunakan adalah metode penelitian deskriptif yang bertujuan untuk mendeskripsikan penggunaan multimedia interaktif pada pembelajaran matematika bangun ruang sisi lengkung. Penelitian ini dilaksanakan di SMP Negeri 2 Gorontalo dengan subjek penelitian adalah siswa-siswi kelas IX yang dipilih secara random. Kelas yang terpilih yaitu kelas IX-1 yang berjumlah 29 orang terdiri dari 12 orang laki-laki dan 17 orang perempuan. Penelitian ini menggunakan teknik analisis deskriptif kuantitatif. Data yang dianalisis terdiri dari kegiatan guru, kegiatan peserta didik, dan angket respon peserta didik.

Data yang diperoleh dianalisis berdasarkan persentase, dengan mengikuti formula berikut:

$$
\text { persentase }=\frac{\sum \text { skor yang diperoleh }}{\sum \text { total skor }} \times 100 \%
$$

Hasil presentasi tersebut selanjutnya dikategorikan berdasarkan kriteria presentasi dengan mengacu pada Tabel 1.

Tabel 1. Kriteria presentasi

\begin{tabular}{cc}
\hline Presentasi $(\mathrm{P})$ & Kategori \\
\hline $81,25<P \leq 100$ & Sangat Baik \\
$62,50<P \leq 81,25$ & Baik \\
$43,75<P \leq 62,50$ & Kurang Baik \\
\hline
\end{tabular}

Sumber: [13]

\section{Hasil dan Pembahasan}

\subsection{Deskrisi Data Hasil Penelitian}

Penggunaan multimedia interaktif pada pembelajaran matematika bangun ruang sisi lengkung tabung dengan subjek penelitian berjumlah 29 orang menggunakan metode penelitian deskriptif kuanitatif. Pada penelitian ini ada tiga instrumen yang digunakan untuk melihat penggunaan multimedia interaktf pada pembelajaran matematika yaitu, Lembar pengamatan kegiatan guru, lembar kegiatan peserta didik, dan angket respon peserta didik. Deskripsi data hasil penggunaan multimedia interaktif dalam pembelajaran disajikan pada Tabel 2.

Tabel 2. Deskripsi data hasil penggunaan multimedia interakif

\begin{tabular}{clcc}
\hline No & \multicolumn{1}{c}{ Sumber Data } & Persentase Capaian & Kategori \\
\hline 1 & Kegiatan Guru & $84 \%$ & Sangat Baik \\
2 & Kegiatan Peserta Didik & $84 \%$ & Sangat Baik \\
3 & Angket Respon Peserta Didik & $85 \%$ & Sangat Baik \\
\hline
\end{tabular}


A.A. Diu, dkk | Deskripsi Penggunaan Multimedia Interaktif pada Pembelajaran Matematika ...

Tabel 2 menunjukkan bahwa data yang diperoleh dari ketiga instrumen mencapai kategori sangat baik.

\subsubsection{Deskripsi Data Kegiatan Guru}

Hasil pengamatan kegiatan guru menggunakan multimedia interaktif pada pembelajaran matematika bangun ruang sisi lengkung tabung selama 3 kali pertemuan dalam kegiatan pembelajaran disajikan pada Tabel 3.

Tabel 3. Deskrpsi data hasil kegiatan guru selama 3 pertemuan

\begin{tabular}{|c|c|c|c|c|c|c|}
\hline \multirow{2}{*}{ No } & \multirow{2}{*}{ Aspek/Indikator } & \multirow{2}{*}{ Jumlah Item } & \multicolumn{3}{|c|}{ Persentase } & \multirow{2}{*}{ Kategori } \\
\hline & & & 1 & 2 & 3 & \\
\hline 1 & $\begin{array}{l}\text { Membuka } \\
\text { pembelajaran }\end{array}$ & 3 & $83 \%$ & $92 \%$ & $92 \%$ & Sangat Baik \\
\hline 2 & $\begin{array}{l}\text { Mengelola } \\
\text { Pembelajaran }\end{array}$ & 10 & $80 \%$ & $80 \%$ & $80 \%$ & Baik \\
\hline 3 & $\begin{array}{l}\text { Menutup } \\
\text { Pembelajaran }\end{array}$ & 3 & $92 \%$ & $92 \%$ & $100 \%$ & Sangat Baik \\
\hline
\end{tabular}

Tabel 3 menunjukan bahwa masing-masing aspek kegiatan guru dalam pembelajaran matematika menggunakan multimedia interaktif memperoleh nilai lebih dari $81,25 \%$. Dengan demikian, kegiatan guru dalam pembelajaran matematika menggunakan multimedia interaktif dalam kategori baik dan sangat baik. Berdasarkan hasil pengamatan bahwa menggunakan multimedia interaktif dalam pembelajaran memudahkan guru dalam menjelaskan yang membuat peserta didik memahami materi sehingga waktu yang digunakan lebih efisien. Hal ini sejalan dengan temuan dalam [14] bahwa penggunaan multimedia interaktif dalam proses pembelajaran memberikan kontribusi positif untuk meningkatkan hasil belajar peserta didik.

\subsubsection{Deskripsi Data Kegiatan Peserta Didik}

Hasil pengamatan kegiatan peserta didik selama 3 kali pertemuan yang dilakukan dalam kegiatan pembelajaran matematika bangun ruang sisi lengkung menggunakan multimedia interaktif materi tabung disajikan pada Tabel 4.

Tabel 4. Persentase kegiatan peserta didik dalam pembelajaran

\begin{tabular}{|c|c|c|c|c|c|c|}
\hline \multirow{2}{*}{ No } & \multirow{2}{*}{ Aspek/Indikator } & \multirow{2}{*}{$\begin{array}{l}\text { Jumlah } \\
\text { Item }\end{array}$} & \multicolumn{3}{|c|}{ Persentase } & \multirow{2}{*}{ Kategori } \\
\hline & & & 1 & 2 & 3 & \\
\hline 1 & $\begin{array}{l}\text { Kerja Sama Peserta Didik } \\
\text { Dalam Pembelajaran }\end{array}$ & 3 & $84 \%$ & $85 \%$ & $86 \%$ & Sangat Baik \\
\hline 2 & $\begin{array}{l}\text { Partisipasi peserta didik } \\
\text { dalam penggunaan } \\
\text { multimedia interaktif }\end{array}$ & 3 & $84 \%$ & $84 \%$ & $84 \%$ & Sangat Baik \\
\hline
\end{tabular}

Tabel 4 menunjukan bahwa persentase kegiatan peserta didik untuk setiap aspek yang diamati pada pada lembar kegiatan peserta didik termasuk dalam kategori sangat baik. Selama pembelajaran berlangsung peserta didik lebih aktif dan tertarik untuk belajar 
A.A. Diu, dkk | Deskripsi Penggunaan Multimedia Interaktif pada Pembelajaran Matematika ...

dikarenakan gambar atau tampilan yang terdapat dalam multimedia sangat menarik. Hal ini sejalan dengan temuan dalam [14] bahwa penggunaan multimedia interaktif dalam proses pembelajaran dapat meningkatkan aktivitas siswa. Dengan begitu suasana pembelajaran menjadi lebih menarik dan menyenangkan.

\subsubsection{Deskripsi Data Respon Peserta Didik}

Hasil persentase pada setiap aspek respon positif peserta didik terhadap pembelajaran matematika menggunakan multimedia interaktif materi tabung yang di peroleh menggunakan angket yang telah dibagikan pada 29 peserta didik kelas IX-1 SMP Negeri 2 Gorontalo di sajikan pada Tabel 5.

Tabel 5. Persentase respon positif peserta didik

\begin{tabular}{clccc}
\hline No & Aspek/Indikator & $\begin{array}{c}\text { Jumlah } \\
\text { Item }\end{array}$ & Persentase & Kategori \\
\hline 1 & $\begin{array}{l}\text { Peserta didik lebih mudah memahami materi } \\
\text { tabung menggunakan multimedia interaktif }\end{array}$ & 5 & $84 \%$ & $\begin{array}{c}\text { Sangat } \\
\text { Baik }\end{array}$ \\
2 & $\begin{array}{l}\text { Peserta didik lebih senang belajar matematika } \\
\text { menggunakan multimedia interaktif khusunya } \\
\text { materi tabung }\end{array}$ & 6 & $85 \%$ & $\begin{array}{c}\text { Sangat } \\
\text { Baik }\end{array}$ \\
$\begin{array}{l}\text { Pembelajaran menggunakan multimedia } \\
\text { interaktif khususnya materi tabung membuat } \\
\text { peserta didik lebih aktif } \\
\text { Peserta didik lebih tekun belajar menggunakan } \\
\text { multimedia interaktif pada materi tabung }\end{array}$ & 3 & $86 \%$ & $\begin{array}{c}\text { Sangat } \\
\text { Baik }\end{array}$ \\
\hline
\end{tabular}

Berdasarkan Tabel 5, dapat dilihat bahwa masing-masing aspek mencapai kriteria sangat baik. Hal ini menunjukkan bahwa pembelajaran menggunakan multimedia interaktif membuat peserta didik senang dan lebih tekun dalam belajar.

\subsection{Pembahasan}

Penelitian ini bertujuan untuk mengambarkan penggunaan multimedia interaktif pada pembelajaran matematika bangun ruang sisi lengkung pada topik tabung. Sebelum melakukan kegiatan pembelajaran guru mempersiapkan perangkat pembelajaran berupa RPP, media pembelajaran berbasis multimedia interaktif dan perangkat pembelajaran lainnya. Pada kegiatan awal pembelajaran guru memotivasi peserta didik untuk belajar dengan melakukan apresepsi menggunakan multimedia interaktif dimana animasi yang ditampilkan menarik perhatian peserta didik. Selanjutnya masuk pada kegiatan inti guru menggunakan metode pembelajaran yang sudah disiapkan sebelumnya. Metode yang digunakan yaitu metode diskusi, tanya jawab dan lain-lain.

Guru menjelaskan materi tabung menggunakan multimedia interaktif dan mendorong peserta didik untuk menyimak materi yang ditampilkan dalam multimedia interaktif, kemudian memberikan kesempatan kepada peserta didik untuk bertanya jika ada materi yang belum dipahami. Setelah itu guru membagi peserta didik kedalam beberapa kelompok untuk menyelesaikan masalah yang terdapat dalam LKPD serta meminta dan membimbing peserta didik mengerjakan latihan soal yang ada di dalam multimedia interaktif. Kegiatan akhir guru melakuka refleksi pelajaran dan meminta peserta didik untuk menyimpulkan materi yang sudah diajarkan. Hasil pengamatan yang dilakukan 
oleh observer selama kegiatan pembelajaran berlangsung yang diisi di dalam lembar pengamatan menunjukan bahwa kegiatan guru dalam pengguanan multimedia interaktif pada pembelajaran matematika materi tabung sangat baik. Dimana hasil pengamatan kegiatan guru pada pertemuan pertama untuk aspek membuka pelajaran memperoleh persentase $83 \%$, mengelola pembelajaran $80 \%$, dan menutup pembelajaran $92 \%$, pertemuan kedua aspek membuka pelajaran memperoleh persentase $92 \%$, mengelola pembelajaran $80 \%$, dan menutup pembelajaran $92 \%$, dan pertemuan ketiga aspek membuka pelajaran memperoleh persentase $92 \%$, mengelola pembelajaran $80 \%$, dan menutup pembelajaran $100 \%$. Hasil ini mendukung temuan yang terdapat pada [15] bahwa multimedia interaktif efektif digunakan dalam proses pembelajaran matematika, karena siswa dengan mudah memahami materi pembelajaran yang disampaikan.

Selama kegiatan pembelajaran menggunakan multimedia interaktif berlangsung peserta didik antusias dan lebih aktif karena materi yang ditampilkan dalam multimedia interaktif sangat jelas serta animasinya menarik. Hal ini ditunjukan dengan hasil pengamatan yang dilakukan oleh beberapa orang observer kegiatan peserta didik dalam pembelajaran menggunakan multimedia interaktif selama 3 kali pertemuan untuk aspek kerja sama peserta didik dalam pembelajaran memperoleh persentase $84 \%, 85 \%, 86 \%$ dan aspek partisipasi peserta didik dalam penggunaan multimedia interaktif memperoleh persentase $84 \%, 84 \%$, dan $84 \%$. Setelah pembelajaran berakhir peserta didik dibagikan angket untuk diisi. Berdasarkan angket tersebut respon peserta didik terhadap pembelajaran menggunakan multimedia sangat baik. Hal ini dibuktikan dengan hasil yang di peroleh dari masing-masing aspek yaitu aspek peserta didik lebih mudah memahami materi tabung menggunakan multimedia interaktif memperoleh persentase $84 \%$, peserta didik lebih senang belajar matematika menggunakan multimedia interaktif khususnya materi tabung 85\%, pembelajaran menggunakan multimedia interaktif khususnya materi tabung membuat peserta didik lebih aktif $86 \%$, dan peserta didik lebih tekun belajar menggunakan multimedia interaktif pada materi tabung $85 \%$. Berdasarkan hasil pengamatan kegiatan guru, kegiatan peserta didik dan angket respon peserta didik disimpulkan bahwa multimedia interaktif sangat baik digunakan dalam pembelajaran. Hal ini sejalan dengan hasil yang dipaparkan pada [16] bahwa multimedia interaktif efektif digunakan dalam pembelajaran. Hal ini dibuktikan dengan kemampuan guru mengelola pembelajaran yang berada dalam katagori baik yaitu sebesar $80 \%$, ketuntasan hasil belajar sebesar $80 \%$ dan hasil respon siswa yang menunjukkan lebih dari $90 \%$ siswa tertarik pada penampilan ilustrasi/gambar multimedia interaktif dan berminat untuk mengikuti pembelajaran selanjutnya.

\section{Kesimpulan}

Penggunaan multimedia interaktif pada pembelajaran matematika bangun ruang sisi lengkung tabung mencapai kategori sangat baik berdasarkan indikator, kemapuan guru dalam menggunakan multimedia interaktif dalam pembelajaran dengan rata-rata persentase $84 \%$, aktifitas peserta didik dalam pembelajaran menggunakan multimedia interaktif dengan rata-rata persentase $84 \%$, dan respon positif peserta didik terhadap penggunaan multimedia interaktif pada pembelajaran dengan nilai persentase lebih dari $81,25 \%$.

\section{Referensi}

[1] H. Surjono, Multimedia Pembelajaran Interaktif: Konsep dan Pengembangan. 
A.A. Diu, dkk | Deskripsi Penggunaan Multimedia Interaktif pada Pembelajaran Matematika ...

Yogyakarta: UNY Press, 2017.

[2] C. Devi, T. S. G. Utari, and M. Nurkanti, "Penggunaan media pembelajaran MIVI (Media Interaktif Visual) untuk meningkatkan hasil belajar siswa pada topik sistem gerak manusia," J. BIOEDUKATIKA, vol. 6, no. 1, pp. 1-7, Jun. 2018.

[3] A. S. S. Harningsih and E. Napitupulu, "Penggunaan Multimedia Pembelajaran Interaktif dan Kreativitas terhadap Hasil Belajar Teknologi Informasi dan Komunikasi (TIK)," J. Teknol. Inf. Komun. Dalam Pendidik., vol. 1, no. 1, pp. 24-37, Jan. 2015.

[4] Y. Andinny and I. Lestari, "Pengaruh Pembelajaran Multimedia terhadap Hasil Belajar Matematika," J. Kaji. Pendidik. Mat., vol. 1, no. 2, pp. 169-179, 2016.

[5] A. Atmawarni, "Penggunaan Multimedia Interaktif Guna Menciptakan Pembelajaran yang Inovatif di Sekolah," PERSPEKTIF, vol. 1, no. 1, pp. 20-27, Jan. 2016.

[6] V. Damopolii, N. Bito, and R. Resmawan, "Efektifitas Media Pembelajaran berbasis Multimedia pada Materi Segiempat," Algoritm. J. Math. Educ., vol. 1, no. 2, pp. 74-85, 2019.

[7] P. U. Suseno, Y. Ismail, and S. Ismail, "Pengembangan Media Pembelajaran Matematika Video Interaktif berbasis Multimedia," Jambura J. Math. Educ., vol. 1, no. 2, pp. 59-74, 2020.

[8] B. Baiduri, M. Taufik, and L. Elfiani, "Pengembangan Media Pembelajaran PopUp Book Berbasis Audio Pada Materi Bangun Datar Segiempat Di SMP," Aksioma J., vol. 8, no. 1, pp. 248-261, 2019.

[9] M. Istiqlal, "Pengembangan Multimedia Interaktif dalam Pembelajaran Matematika," JIPMat, vol. 2, no. 1, pp. 43-54, Jul. 2017.

[10] D. A. Albar, A. Buchori, and Y. H. Murtianto, "Pengembangan Multimedia Interaktif dalam Pembelajaran Matematika dengan Pendekatan Kontekstual Ditinjau dari Pemahaman Konsep Siswa," MUST J. Math. Educ. Sci. Technol., vol. 2, no. 2, pp. 221-230, Dec. 2017.

[11] I. D. Kurniawati and S.- Nita, "Media Pembelajaran Berbasis Multimedia Interaktif untuk Meningkatkan Pemahaman Konsep Mahasiswa," DOUBLECLICK J. Comput. Inf. Technol., vol. 1, no. 2, pp. 68-75, Feb. 2018.

[12] S. Prastya and M. K. Umam, "Efektivitas Penggunaan Media Pembelajaran Elektronik Interaktif pada Hasil Belajar Materi Kesetimbangan," J. Pendidik. Vokasional Tek. Mesin, vol. 3, no. 4, pp. 263-270, 2015.

[13] P. A. M. Ariyawati, J. Waluyo, and J. Prihatin, "Analisis Respon Siswa Terhadap Model Pairs, Investigation and Communication (PIC) dalam Pembelajaran IPA," J. Pembelajaran dan Pendidik. Sains, vol. 2, no. 1, pp. 9-15, 2017.

[14] N. Bito, S. Ismail, and R. D. R. Dako, "The Application Design of Interactive Multimedia of IT- based Mathematics Learning on Strengtening Students ' Characters," Int. J. Sci. Basics Aplied Res., vol. 39, no. 2, pp. 129-138, 2018.

[15] N. Bito, S. Ismail, and R. D. R. Dako, "The Development of Character BuildingBased TwoDimensional Shapes Multimedia on Junior High School Students in Gorontalo Province, Indonesia," Int. J. Sci. Basics Aplied Res., vol. 48, no. 1, pp. 115125, 2019.

[16] A. Syukria, "Efektivitas Penggunaan Multimedia Interaktif pada Materi Dimensi Tiga," Al Khawarizmi J. Pendidik. dan Pembelajaran Mat., vol. 1, no. 2, pp. 102-112, Dec. 2017. 